\title{
Kartagener syndrome: A case report
}

\author{
Rahaf Ibrahim MA, PD, Huda Daood, MD, CCP
}

R Ibrahim, H Daood. Kartagener syndrome: A case report. Can J Respir Ther 2021;57:44-48. doi: 10.29390/cjrt-2020-064.

\begin{abstract}
Kartagener syndrome is a rare, autosomal recessive genetic disorder that causes defects in the action of ciliary movement, comprises of triad situs inversus, chronic sinusitis, and bronchiectasis. We present the case of a 3-year-old boy with repeated respiratory infections and pneumonic infections presenting with acute respiratory failure. He was diagnosed with Kartagener syndrome based on his clinical presentation and imaging features. The current diagnosis was consistent with severe acute bronchitis. He was managed initially with conventional medical therapy, but he didn't respond and was transferred immediately to the pediatric intensive care unit where noninvasive ventilation was administered. He had shown significant predictors of early noninvasive ventilation failure and was mechanically ventilated, after which, he was disconnected from the ventilator and discharged without complications. In patients presenting with recurrent upper and lower respiratory tract infections, Kartagener syndrome should always be kept in mind. The correct diagnosis of this disorder in early life is very important to prevent complications and improve patients' quality of life.
\end{abstract}

Key Words: Kartagener syndrome; primary ciliary dyskinesia; situs inversus; bronchiectasis; dextrocardia; non-invasive ventilation.

\section{INTRODUCTION}

Kartagener syndrome (KS) is a subset of a larger group of ciliary motility disorders called primary ciliary dyskinesias (PCDs) [1]. KS is an inherited autosomal recessive disorder that causes defects in the action of ciliary movement, comprises of triad sinusitis, situs inversus, and bronchiectasis [2]. Siewert [3] first explained the combination of situs inversus, chronic sinusitis, and bronchiectasis in 1904. Manes Kartagener [4] first recognized this clinical triad as a congenital syndrome in 1933 and described this syndrome bearing his name. Its estimated incidence is approximately 1 in 30,000 live births [5]. Normal ciliary function is critical for respiratory host defense and motility of sperm and ensures proper visceral orientation during embryogenesis. In KS, the gene mutation at DNAI1 and DNAH5 leads to impaired ciliary motility, which predisposes to recurrent sinopulmonary infections, infertility, and errors with left-right body orientation [5]. Males and females are affected equally [6].

This case report describes the case of a 3 -year-old boy with KS, reported here due to its rarity. While many studies have investigated KS, a search of medical English literature did not result in any published works dealing with the management of a child with KS in the pediatric intensive care unit (PICU). This syndrome should be kept in mind in differential diagnoses of chronic respiratory infections and must be diagnosed as early as possible to improve patient's quality of life. Appropriate and early treatment and care of these patients can improve prognosis and prevent the progress of respiratory problems such as bronchiectasis and pneumonia. This study aims to contribute toward a greater understanding of KS.

\section{ETHICS APPROVAL}

The patient's mother consented to the publication of this deidentified case report. Institutional review board approval is not required for deidentified single case reports or histories based on institutional policies.

\section{CASE REPORT}

A 3-year-old male patient was assessed in the pediatric emergency department on 3 June 2020 for a 3-day history of fever and shortness of breath and a 2-day history of productive cough. His mother denied having any history of chills or hemoptysis. Review of systems was unremarkable. There was no history of travel outside Damascus city in the recent past. He had no exposure to birds or contact with sick persons. He had no pets at home. There were no smokers in the home. His mother said that he had a history of frequent colds and repeated respiratory infections. He also suffered repeated pneumonic infections. There was no history of allergy, sleep apnea, and weight loss. No family history of asthma or atopy was present. Family history revealed that his sister was once diagnosed with right-sided heart by a clinician on routine examination. She had no history of repeated respiratory infections or repeated pneumonic infections. His parents were healthy and not related. His mother reported no problems during pregnancy.

In the emergency department (ED), the patient was reported to be in severe respiratory distress. Vital signs revealed temperature of $38^{\circ} \mathrm{C}$, respiratory rate of 50 breaths per minute, heart rate of 120 beats per minute, blood pressure of $110 / 60 \mathrm{~mm} \mathrm{Hg}$, and oxygen saturations of $75 \%$ on room air. The infant appeared acutely ill. He was diaphoretic. Physical exam revealed nasal flaring, with severe suprasternal, intercostal, and subcostal retractions. On cardiovascular examination, apex beat was felt on right fourth intercostal space along midclavicular line. Heart sounds were best audible on the right side of his chest. On chest auscultation, there was diminished air movement in both lungs, bilateral wheeze, coarse crackles at the bases of both lungs were audible, with coarse rhonchi present in both upper lobes. There was no evidence of otitis media with effusion as confirmed by otoscopy. The palatine tonsils were observed to be grade 3 hypertrophic (Brodsky Grading Scale), but with no active infection.

Other physical exam findings were unremarkable. Chest X-ray revealed cardiac apex and aortic arch on right side, suggesting dextrocardia, and right-sided stomach air suggesting a case of situs inversus, with normal lungs fields (Figure 1). A chest computed tomography (CT) scan showed dextrocardia with no radiographic evidence of bronchiectasis (Figure 2). Ultrasound examination of the abdomen showed a normal liver and gall bladder on left side and a normal spleen on right side, suggestive of situs inversus. A CT of the paranasal sinuses revealed sinusitis. The examination showed opacified maxillary and ethmoidal sinus cavities (Figure 3). A CT scan of the abdomen showed liver on the left and spleen on the right, suggestive of situs inversus (Figure 4). Electrocardiogram showed signs of

Pediatric Intensive Care Unit, Children's Damascus University Hospital, Damascus, Syria

Correspondence: Rahaf Ibrahim, Damascus, Syria.Tel: 00963934518980; E-mail:Dr.r.e345@gmail.com

Published online at https://www.cjrt.ca on 21 April 2021

This open-access article is distributed under the terms of the Creative Commons Attribution Non-Commercial License (CC BY-NC) (http:// 


\section{FIGURE 1}

Chest and upper abdomen radiography showing dextrocardia, normal lungs fields and the stomach bubble under the right diaphragm.

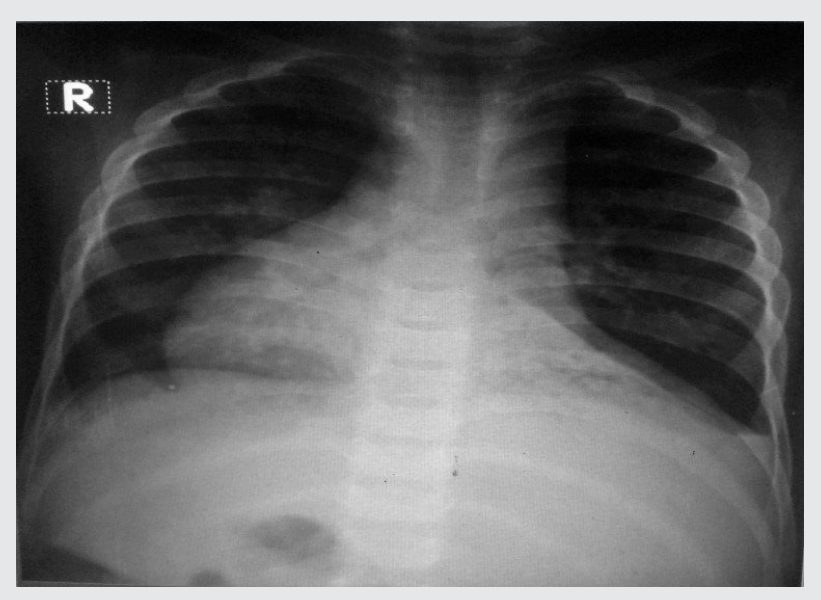

\section{FIGURE 2}

Chest computed tomography showing dextrocardia, with no radiographic evidence of bronchiectasis.

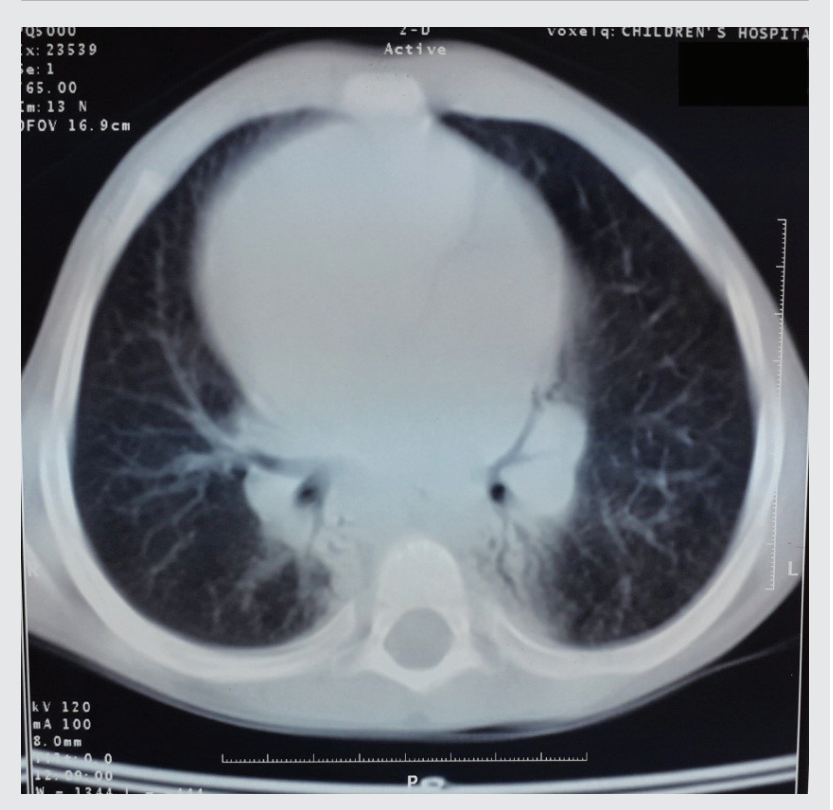

dextrocardia, inverted $\mathrm{P}$ waves in lead $\mathrm{I}$, right axis deviation and QRS complexes get progressively smaller in leads V 1-V 6. Two-dimensional echocardiography was consistent with dextrocardia; all four chambers were normal. Doppler study confirmed situs inversus of aorta and inferior vena cava. Sweat test for chloride was also undertaken to rule out cystic fibrosis and it was negative on two occasions. The tuberculin skin test was negative. Immunoglobulins tests were normal.

\section{Final diagnosis}

A diagnosis of KS was made based on clinical presentation and imaging features. The case represented a classical KS. The current diagnosis was consistent with severe acute bronchitis.

\section{Hospital course}

The patient was initially hospitalized in the ED where he received nebulized salbutamol and ipratropium, intravenous methyl prednisolone, and intravenous magnesium sulfate. The patient was placed on a facial mask with partial rebreathing reservoir, $10 \mathrm{~L} / \mathrm{min} \mathrm{O}_{2}$ was administered with it, and his oxygen saturation was measured as $93 \%$ with pulse oximetry. Initial arterial blood gas (ABG) analysis revealed partially compensated respiratory acidosis with Type 2 (hypercapnic) respiratory failure, $\mathrm{pH}$ 7.26, $\mathrm{PaCO}_{2} 82 \mathrm{mmHg}, \mathrm{PaO}_{2} 83 \mathrm{mmHg}, \mathrm{HCO}_{3}-36 \mathrm{mEq} / \mathrm{L}$, and $\mathrm{SaO}_{2} 94 \%$. Serum electrolytes, renal and liver function tests, and complete blood counts were normal. Two hours after administration of drug treatment, $A B G$ analysis was conducted again. The analysis showed no improvement in the patient's condition. There was no clinical improvement, so the patient was moved to the PICU, where noninvasive ventilation (NIV) was initiated using a full face mask and bilevel positive airway pressure with inspiratory positive airway pressure of $8 \mathrm{~cm} \mathrm{H} \mathrm{H}_{2} \mathrm{O}$, expiratory positive airway pressure of $4 \mathrm{~cm} \mathrm{H}_{2} \mathrm{O}$ and a $\mathrm{FiO}_{2}$ of $50 \%$. $\mathrm{SpO}_{2} / \mathrm{FiO}_{2}$ ratio was 188 . The $\mathrm{ABG}$ values are summarised in Table 1 .

In view of worsening dyspnea and falling saturation, the pressures were gradually increased to 16 and $6 \mathrm{~cm} \mathrm{H}_{2} \mathrm{O}$ respectively, and $\mathrm{FiO}_{2}$ was gradually increased to $90 \%$. ABGs repeated after $2 \mathrm{~h}$ revealed no improvement. As the patient was not improving on NIV and was becoming hypoxemic and agitated, he was given $2 \mathrm{mg} / \mathrm{kg}$ of propofol, and the trachea was intubated in a single attempt using a cuffed tube of internal diameter $4.5 \mathrm{~mm}$. The ventilator was set as synchronized intermittent mandatory ventilation (SIMV) mode with pressure control $16 \mathrm{cmH}_{2} \mathrm{O}$, $\mathrm{FiO}_{2} 0.5$, positive end-expiratory pressure (PEEP) $5 \mathrm{cmH}_{2} \mathrm{O}$, frequency 25 times/min, inspiratory time to expiratory time ratio $1: 3$, pressure support $10 \mathrm{cmH}_{2} \mathrm{O}$, PEEP $5 \mathrm{cmH}_{2} \mathrm{O}$. He was sedated intermittently with intravenous midazolam. Ketamine and intravenous salbutamol were added to meet optimal treatment. ABGs measured after $2 \mathrm{~h}$ of mechanical ventilation were as follows: $\mathrm{pH} 7.30, \mathrm{PaCO}_{2} 65 \mathrm{mmHg}, \mathrm{PaO}_{2}$ $112 \mathrm{mmHg}$, and $\mathrm{SaO}_{2} 99 \%$. A nasogastric tube was inserted for enteral feeding and intermittent oral suctioning was performed. He was continued on scheduled intravenous methyl prednisolone and intravenous magnesium sulfate in the PICU as well. The patient was treated with a combination of antibiotics. The ABG analysis conducted $6 \mathrm{~h}$ after the beginning of the mechanical ventilation found a $\mathrm{pH} 7.38, \mathrm{PaCO}_{2}$ $44 \mathrm{mmHg}, \mathrm{PaO}_{2} 115 \mathrm{mmHg}$, and $\mathrm{SaO}_{2}$ 99\%. Serial ABGs were done and showed marked improvement. On day 4 , he had clear consciousness with adequate cough reflex and stable cardiovascular function. Oxygen saturation remained $98 \%$ or higher after $24 \mathrm{~h}$ had passed since the beginning of ventilation using a T-piece, and $3 \mathrm{~L} / \mathrm{min}$ of oxygen was provided to the patient. $\mathrm{PaCO}_{2}$ was $40 \mathrm{mmHg}$. Thereafter, extubation was done.

After extubation, $\mathrm{O}_{2} 5 \mathrm{~L} / \mathrm{min}$ was applied via facial mask with partial rebreathing reservoir and he was observed closely. Thirty minutes later, the $\mathrm{ABG}$ analysis was $\mathrm{pH} 7.45, \mathrm{PaCO}_{2} 40 \mathrm{mmHg}, \mathrm{PaO}_{2} 120 \mathrm{mmHg}$, and $\mathrm{SaO}_{2} 99 \%$.

The patient had no complication during the PICU stay and was subsequently discharged from the PICU on day 5 , with $\mathrm{pH} 7.48, \mathrm{PaCO}_{2}$ $42 \mathrm{mmHg}, \mathrm{PaO}_{2} 102 \mathrm{mmHg}, \mathrm{HCO}_{3}-33 \mathrm{mEq} / \mathrm{L}$, and $\mathrm{SaO}_{2} 99 \%$, and blood test results were in the normal range. Chest X-ray showed no infiltrates. Then, he was treated with orally administered antibiotics, mucolytic, bronchodilator and chest physiotherapy. He was symptomatically better with the above therapy and started on long-term low-dose prophylactic antibiotic. He was advised for influenza and pneumococcus vaccines. He was then referred to regular follow-up in otolaryngology, pulmonology, and general pediatric medicine. After 2 months of follow-up, the patient is doing well.

\section{DISCUSSION}

Disorders of ciliary motility may be congenital or acquired. Congenital disorders are labeled as PCDs. Nearly 50\% of PCD patients have situs inversus. Such cases of PCD with situs inversus are known as Kartagener's syndrome [1]. Clinical symptoms in PCD varies, some may begin with neonatal respiratory distress, or later develop chronic productive cough, 


\section{FIGURE 3}

Computed tomography of paranasal sinuses showing sinusitis. The examination showed opacified maxillary and ethmoidal sinus cavities.
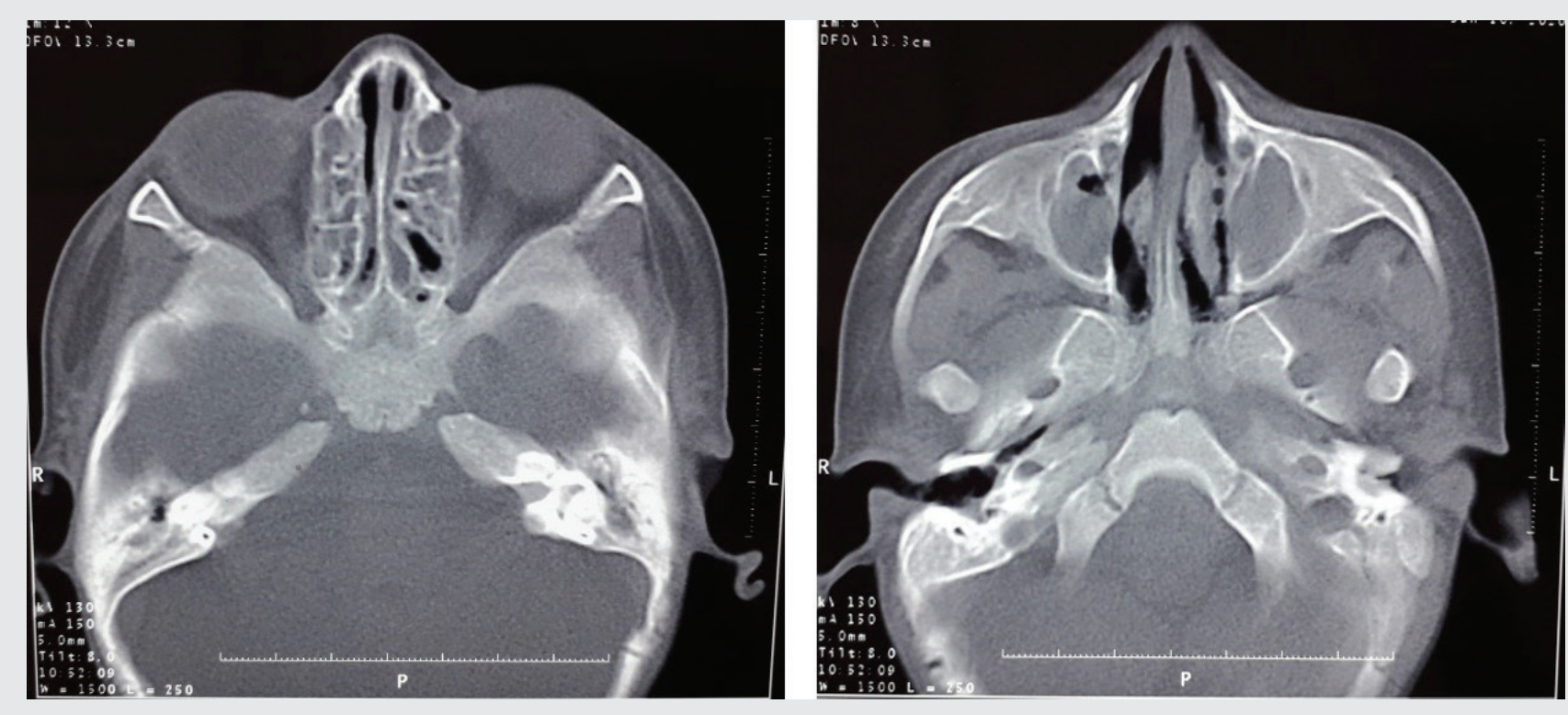

\section{FIGURE 4}

Computed tomography scan of the abdomen showing liver on the left and spleen on the right.

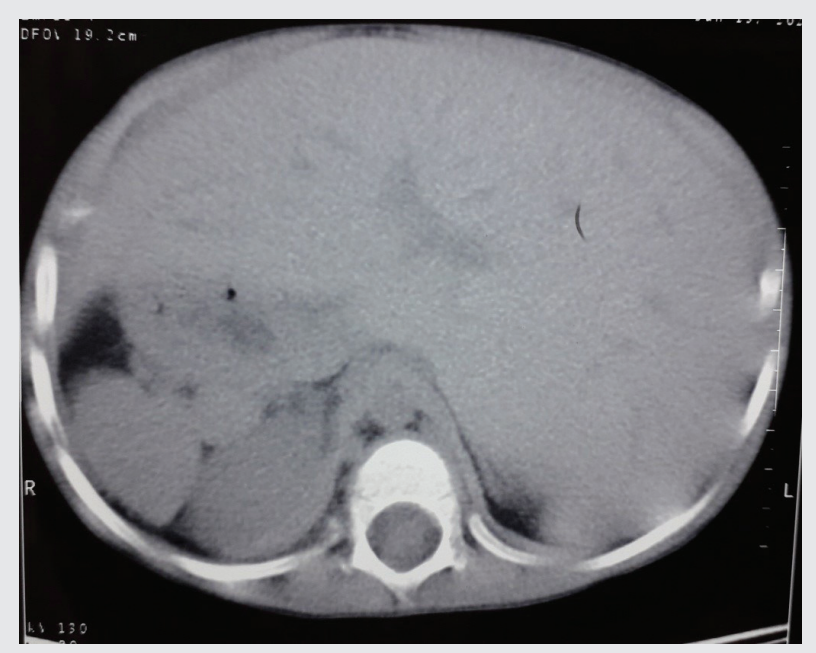

due to bronchiectasis, nonresponsive to treatment atypical asthma, chronic rhinosinusitis and otitis, ectopic pregnancy and subfertility in women, or male infertility [7]. Clinical and radiographic evidence of bronchiectasis develops as the disease progresses; bronchiectasis and obstructive impairment may be apparent in preschool children [8]. In our case, bronchiectasis had not developed yet.

Normal ciliary beating is also necessary for visceral rotation and orientation during embryonic development. Patients with KS may have either situs solitus where there is dextrocardia only or situs inversus totalis, where all the visceral structures are on the opposite side [2]. In this case, it was a situs inversus totalis because the cardiac position, as well as the abdominal viscera, was a mirror image of the normal anatomy.
Most of the disease-causing mutations are said to involve two genes coding for the dynein axonemal heavy chain 5 (DNA H5) and dynein axonemal intermediate chain 1 (DNA I1) [9]. The complete syndrome has high familial evidence, appearing only in one generation and multiple siblings. These features and the high incidence of consanguinity among the apparently normal parents of affected children support the contention that the genetic abnormality is carried as an autosomal recessive gene [6]. In our case, family history revealed that his sister was diagnosed with right-sided heart by a routine examination, we recommended further investigations.

The diagnostic criteria recommended for this syndrome include history of chronic bronchial infection and rhinitis from early childhood, combined with one or more of following features: (i) situs inversus or dextrocardia in a patient or a sibling, (ii) alive but immotile spermatozoa, (iii) absent or impaired tracheobronchial clearance, and (iv) cilia showing characteristic ultrastructural defect on electron microscopy [5]. According to this diagnostic criteria, diagnosis of $\mathrm{KS}$ was made in our patient.

Diagnosis can be made by tests to prove impaired cilia function, biopsy, and genetic studies. Semen analysis of postpubertal males may reveal either abnormal sperm motility or aspermia [10]. The Saccharin test is also used for diagnosis. It as a screening test to detect abnormal mucociliary clearance. This test measures the time taken for a pellet of saccharin placed on the inferior turbinate to be tasted, $30 \mathrm{~min}$ is the cutoff point that discriminates normal people from patients with impaired nasal mucociliary clearance. [11]. Measuring exhaled nasal nitric oxide involves measurement of the expired NO from one nostril. There are no agreed cut-off values but nasal nitric oxide levels in patients with PCD are consistently only $10 \%-20 \%$ of the average normal values [12].

Mucociliary transport, which is reduced in these patients, can be measured in situ by administering an inhalation aerosol of colloid albumin tagged with 99Tc. This test uses aerosol particles tagged with 99mTc and external measurement of the radioactivity [13]. Electron microscopy of a nasal or bronchial biopsy can reveal defected cilia structure. Genetic testing for mutations in the genes DNAI1 and DNAH5 is available through specialized laboratories [14]. In the present case, these tests were not performed because of the technical condition in our hospital. However, these procedures are invasive and available only at specialized 


\section{TABLE 1}

Changes in blood gas during the clinical course

\begin{tabular}{|c|c|c|c|c|c|c|c|c|}
\hline Time & & & $\mathrm{pH}$ & $\begin{array}{c}\mathrm{PaCO}_{2} \\
(\mathrm{mmHg})\end{array}$ & $\begin{array}{c}\mathrm{PaO}_{2} \\
(\mathrm{mmHg})\end{array}$ & $\begin{array}{c}\mathrm{HCO}_{3}^{-} \\
(\mathrm{mmol} / \mathrm{L})\end{array}$ & $\begin{array}{c}\mathrm{SaO}_{2} \\
(\%)\end{array}$ & $\begin{array}{c}\mathrm{SpO}_{2} \\
(\%)\end{array}$ \\
\hline ED & Facial mask & $\mathrm{O}_{2} 10 \mathrm{~L} / \mathrm{min}$ & 7.26 & 82 & 83 & 36 & 94 & 93 \\
\hline $\mathrm{H} 2$, ED & Facial mask & $\mathrm{O}_{2} 10 \mathrm{~L} / \mathrm{min}$ & 7.27 & 80 & 85 & 37 & 95 & 94 \\
\hline $\mathrm{HO}, \mathrm{PICU}$ & BiPAP & $\begin{array}{l}8 / 4 \mathrm{cmH}_{2} \mathrm{O} \\
\mathrm{FiO}_{2} \% 50\end{array}$ & 7.26 & 81 & 90 & 38 & 96 & 95 \\
\hline $\mathrm{H} 1$ & BiPAP & $\begin{array}{l}12 / 5 \mathrm{cmH}_{2} \mathrm{O} \\
\mathrm{FiO}_{2} \% 85\end{array}$ & 7.26 & 79 & 92 & 37 & 97 & 96 \\
\hline $\mathrm{H} 2$ & BiPAP & $\begin{array}{l}16 / 6 \mathrm{cmH}_{2} \mathrm{O} \\
\mathrm{FiO}_{2} \% 90\end{array}$ & 7.28 & 77 & 101 & 35 & 94 & 94 \\
\hline $\mathrm{H} 4$ & SIMV & & 7.30 & 65 & 112 & 34 & 99 & 98 \\
\hline $\mathrm{H} 10$ & SIMV & & 7.38 & 44 & 115 & 32 & 99 & 97 \\
\hline $\mathrm{H} 75$ & T-piece & $\mathrm{O}_{2} 3 \mathrm{~L} / \mathrm{min}$ & 7.44 & 40 & 122 & 30 & 98 & 96 \\
\hline H75.5 & Facial mask & $\mathrm{O}_{2} 5 \mathrm{~L} / \mathrm{min}$ & 7.45 & 40 & 120 & 29 & 99 & 98 \\
\hline H100 & Nasal cannula & $\mathrm{O}_{2} 2 \mathrm{~L} / \mathrm{min}$ & 7.48 & 42 & 102 & 33 & 99 & 98 \\
\hline
\end{tabular}

Note: VS, ventilatory support; $\mathrm{PaCO}_{2}$, partial pressure of carbon dioxide in arterial blood; $\mathrm{PaO}_{2}$, partial pressure of oxygen in arterial blood; $\mathrm{HCO}_{3}^{-}$, bicarbonate concentration; $\mathrm{SaO}_{2}$, hemoglobin oxygen saturation of arterial blood; ED, emergency department; $\mathrm{H}$, hour; PICU, pediatric intensive care unit; BiPAP, bi-level positive airway pressure; SIMV, synchronized intermittent mandatory ventilation.

centers; therefore, the diagnosis of KS in this case was clinical, supported by imaging studies.

As a genetic disease, KS has no definite treatment. Treatment of patients is symptomatic and includes intermittent or constant oral or intravenous administration of antibiotics to treat respiratory infections. Bronchiectasis and pneumonia should be treated with inhaling bronchodilators, mucolytics, oral corticosteroids, and chest physiotherapy. Administration of influenza and pneumococcus vaccines is also necessary to prevent frequent infections [15]. Although there is no specific treatment for this rare syndrome, failure to diagnose this may subject the patient to unnecessary repeated admissions to hospitals, investigations, and inappropriate treatment. Tang et al. [16] reported successful functional endoscopic sinus surgery in a 17 -year-old female patient.

Lin [17] reported successful pulmonary surgery in a 23-year-old man, which involved left middle lobectomy. For end-stage KS, double lung transplantation may be useful. Wang et al. [18] reported successful pulmonary surgery in a 49-year-old woman, which involved double lung transplantation.

Early diagnosis and clinical follow-up at regular intervals are essential in these patients to prevent complications. On follow-up, our case improved significantly, which emphasizes the fact that early diagnosis and treatment of this rare syndrome significantly improves the quality of life and prognosis of the patients. Late diagnosis with established bronchiectasis worsens the prognosis, even with the best of treatment methods. A high degree of suspicion about KS among pediatricians around the world is very important.

NIV is being increasingly used in children with acute respiratory failure (ARF), to prevent complications associated with invasive mechanical ventilation. Nunes et al. [19] studied the efficacy of NIV in children with ARF or chronic respiratory failure. They concluded that NIV can be effective in children and infants with ARF, preventing some patients from deteriorating and/or from being ventilated [19]. The case presented here was managed initially with conventional medical therapy, and once the patient didn't respond to medical treatment, he was transferred immediately to the PICU and NIV was administered within $2 \mathrm{~h}$ of admission to the ED. Carrillo et al. [20] performed a study to assess the characteristics and predictors of outcome of patients with community-acquired pneumonia and severe ARF treated with NIV. They concluded that, if predictors for NIV failure are present, avoiding delayed intubation of patients with de novo ARF would potentially minimize mortality [20]. In our case, we kept a strict watch on our patient, and he was mechanically ventilated at the earliest sign of deterioration, after $2 \mathrm{~h}$ of administering NIV.
Grande et al. [21] reported that tachypnea was a predictive factor of failure NIV in PICU [21]. Bernet et al. [22] indicated that there was a significantly higher $\mathrm{FiO}_{2}$ in patients who failed NIV than in responders. An $\mathrm{FiO}_{2}$ of $>80 \%$ after $1 \mathrm{hr}$ of NIV predicted nonresponse in infants and children with respiratory failure for a wide range of reasons [22]. Dohna-Schwake et al. [23] showed that low pH 1-2 hr after start of NIV is associated with NIV failure [23]. Mayordomo-Colunga et al. [24] found $\mathrm{SpO}_{2} / \mathrm{FiO}_{2}$ ratio to be a reliable predictor of early NIV failure in children with ARF. In patients failing before $6 \mathrm{~h}$ the optimal cutoff value suggested of SF ratio at $1 \mathrm{~h}$ to detect early NIV failures was 193 [24].

In our case, repeated clinical assessment and ABGs measurements were done to judge the efficacy of NIV and the need for invasive ventilation. Our patient had shown significant predictors of early NIV failure at the end of the second hour of NIV. The respiratory rate of the patient increased. We needed to increase pressures and $\mathrm{FiO}_{2}$. The respiratory acidosis didn't improve, and $\mathrm{pH}$ stilled low. $\mathrm{SpO}_{2} / \mathrm{FiO}_{2}$ ratio was deteriorated. $\mathrm{SpO}_{2} / \mathrm{FiO}_{2}$ ratio at $1 \mathrm{~h}$ was 112 . According to that the decision of intubation was made. After which he was disconnected from the ventilator and discharged without complications.

\section{CONCLUSION}

A high index of suspicion is needed to make an early diagnosis so that timely treatment options may be offered to prevent problems associated with it. The correct diagnosis of KS in early life is essential in the overall prognosis of the syndrome, as many of the long-term complications can be prevented if timely management is instituted, as was done in this case.

\section{DISCLOSURES}

Author contributions

All authors contributed to the development of the manuscript and the care of the patient presented. All authors approved the final manuscript.

\section{Declaration of conflicting interests}

The authors declared no potential conflicts of interest with respect to the research, authorship, and/or publication of this article.

\section{Funding}

The authors received no financial support for the research, authorship, and/or publication of this article.

\section{Informed consent}

The patient's mother consented to the publication of this deidentified case report. 


\section{Ethical approval}

Institutional review board approval is not required for deidentified single case reports or histories based on institutional policies.

\section{REFERENCES}

1. Palange AA, Shahid AM, Sisode MS, Vaishnav B. Kartagener's syndrome: case report. Int J Healthcare Biomed Res. 2013;2(1):67-69.

2. Ahmed Z, Waseem W, Saman U. Kartagener's syndrome presenting as bilateral recurrent nasal polyposis in a young boy. J Bahria Univ Med Dent Coll 2018;8(4):274-277.

3. Siewert AK. Ueber einen Fall van Bronchiectasie bei einem patienten mito Situs inversus viscerum. Berlin Klin Wochen schr 1904;6:139-141.

4. Kartagener M. Zur pathogenese der bronchiektasien. Beiträge zur Klinik der Tuberkulose und spezifischen Tuberkulose-Forschung 1933;84(12):73-85. doi: 10.1007/BF02140428.

5. Tadesse A, Alemu H, Silamsaw M, Gebrewold Y. Kartagener's syndrome: a case report. J Med Case Rep 2018;12(1):1-4. doi: 10.1186/ s13256-017-1538-2.

6. Casanova MS, Tuji FM, Yoo HJ, Haiter-Neto F. Kartagener syndrome. Dentomaxillofacial Radiol 2006;355:386-389. doi: 10.1259/dmfr/58545230.

7. Rugină AL, Dimitriu AG, Nistor N, Mihăilă D. Primary ciliary dyskinesia diagnosed by electron microscopy in one case of Kartagener syndrome. Rom J Morphol Embryol 2014;55(2):697-701.

8. Leigh MW, Pittman JE, Carson JL, et al. Clinical and genetic aspects of primary ciliary dyskinesia/Kartagener syndrome. Genet Med 2009;11(7):473-487. doi: 10.1097/GIM.0b013e3181a53562.

9. Pandey AK, Maithani T, Bhardwaj A. Kartagener's syndrome: a clinical reappraisal with two case reports. Egyptian J Ear Nose Throat Allied Sci 2014;15(3):271-274. doi: 10.1016/j.ejenta.2014.06.001.

10. Pandit S, Choudhury S, Das A, Basuthakur S, Das SK. A rare case of Kartagener's syndrome. J Nat Sci Biol Med 2014;5(1):175. doi: 10.4103/0976-9668.127321.

11. Corbo GM, Foresi A, Bonfitto P, Mugnano A, Agabiti N, Cole PJ. Measurement of nasal mucociliary clearance. Arch Dis Child 1989;64(4):546-50. doi: 10.1136/adc.64.4.546.

12. Dalrymple RA, Kenia P. European respiratory society guidelines for the diagnosis of primary ciliary dyskinesia: a guideline review. Arch Dis Child Educ Pract 2018;104(5). doi: 10.1136/archdischild-2017-312902.
13. Camner P, Mossberg B, Afzelius BA. Measurements of tracheobronchial clearance in patients with immotile-cilia syndrome and its value in differential diagnosis. Eur J Respir Dis 1983;127:57-63.

14. Skeik N, Jabr FI. Kartagener syndrome. Int J Gen Med 2011;4:41. doi: 10.2147/IJGM.S16181.

15. Najafi S, Mohammadpour A, Eshghizadeh M. Kartagener syndrome: a case report. Asian J Pharm Clin Res 2018;11(5):7-9. doi: 10.22159/ ajpcr.2018.v11i5.25593.

16. Tang X, Zou J, Liu S. Endoscopic sinus surgery for treatment of Kartagener syndrome: a case report. Balkan Med J 2013;30(2):244. doi: 10.5152/balkanmedj.2013.8152.

17. Lin H, Cao Z, Zhao X, Ye Q. Left middle lobectomy for bronchiectasis in a patient with Kartagener syndrome: a case report. J Cardiothorac Surg 2016;11(1):37. doi: 10.1186/s13019-016-0426-y.

18. Wang B, Zhang X, Jiang W, et al. Double lung transplantation for endstage Kartagener syndrome: a case report and literature review. J Thorac Dis 2020;12(4):1588. doi: 10.21037/jtd.2020.02.28.

19. Nunes P, Abadesso C, Almeida E, et al. Ventilação não invasiva numa unidade de cuidados intensivos pediátricos. Acta Médica Portuguesa 2010:399-404.

20. Carrillo A, Gonzalez-Diaz G, Ferrer M, et al. Non-invasive ventilation in community-acquired pneumonia and severe acute respiratory failure. Intensive Care Med 2012;38(3):458-66. doi: 10.1007/ s00134-012-2475-6.

21. Grande RAA, Fernandes GA, Andrade DP, et al. Noninvasive ventilation in a pediatric ICU: factors associated with failure. J Bras Pneumol 2020;46(6):e20180053.doi: 10.36416/1806-3756/e20180053.

22. Bernet V, Hug MI, Frey B. Predictive factors for the success of noninvasive mask ventilation in infants and children with acute respiratory failure. Pediatr Crit Care Med 2005;6(6):660-4.doi: 10.1097/01. PCC.0000170612.16938.F6.

23. Dohna-Schwake C, Stehling F, Tschiedel E, Wallot M, Mellies U. Noninvasive ventilation on a pediatric intensive care unit: feasibility, efficacy, and predictors of success. Pediatr Pulmonol 2011;46(11):1114-20. doi: 10.1002/ppul.21482.

24. Mayordomo-Colunga J, Pons M, López Y, et al. Predicting noninvasive ventilation failure in children from the $\mathrm{SpO} 2 / \mathrm{FiO} 2$ (SF) ratio. Intensive Care Med 2013;39(6):1095-103. doi: 10.1007/ s00134-013-2880-5. 